This item was submitted to Loughborough's Research Repository by the author.

Items in Figshare are protected by copyright, with all rights reserved, unless otherwise indicated.

\title{
Dynamics and particle fluxes in atmospheric-pressure electronegative radio frequency microplasmas
}

\section{PLEASE CITE THE PUBLISHED VERSION}

http://dx.doi.org/10.1063/1.3631758

\section{PUBLISHER}

(c) American Institute of Physics

\section{VERSION}

AM (Accepted Manuscript)

\section{PUBLISHER STATEMENT}

This work is made available according to the conditions of the Creative Commons Attribution-NonCommercialNoDerivatives 4.0 International (CC BY-NC-ND 4.0) licence. Full details of this licence are available at: https://creativecommons.org/licenses/by-nc-nd/4.0/

\section{LICENCE}

CC BY-NC-ND 4.0

\section{REPOSITORY RECORD}

McKay, Kirsty, Ding-Xin Liu, Ming-Zhe Rong, Felipe Iza, and Michael G. Kong. 2019. "Dynamics and Particle Fluxes in Atmospheric-pressure Electronegative Radio Frequency Microplasmas". figshare. https://hdl.handle.net/2134/22150. 


\title{
Dynamics and particle fluxes in atmospheric-pressure electronegative rf microplasmas
}

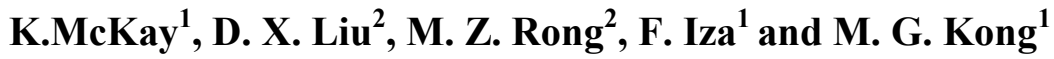 \\ ${ }^{1}$ Dept. Electronic and Electrical Engineering, Loughborough University, LE11 3TU, \\ $\mathrm{UK}$ \\ ${ }^{2}$ State Key Laboratory of Electrical Insulation and Power Equipment, Xi'an Jiaotong \\ University, 710049, P. R. China
}

We report on intricate dynamics observed in atmospheric-pressure rf electronegative discharges where electrons and anions are separated due to their different mobility. This results in the formation of positively charged regions between an electronegative plasma core and an oscillating electron ensemble. It is found that for a given input power, the electron, ion (both positive and negative) and neutral fluxes increase as the gap size is reduced, resulting in a more efficient delivery of chemical species to a treated target. 
In recent years low-temperature atmospheric-pressure microplasmas have received growing attention for their potential use in many technological applications including displays, radiation sources, analytical systems, millimetre/microwave devices, material processing and biomedical applications. ${ }^{1,2,3}$, ${ }^{4}$ The reduced dimension of microplasmas favour stable operation at high pressure and enable the integration of microplasmas in portable devices.

Besides the obvious difference in terms of size, the discharge dynamics in microplasmas differ from conventional low-pressure large-scale reactors. In microplasmas, sheaths can become comparable to the source size, ${ }^{5,6}$ enabling interesting possibilities such as electrode/sample bombardment by energetic electrons and enhancement of the high energy tail of the electron energy distribution function. ${ }^{6}$ These observations have been made for electropositive discharges. Microplasma applications, however, may also demand operation in electronegative environments. For example, in the fast growing field of plasma medicine, ${ }^{7,8}$ oxygen, an electronegative gas, is often introduced as a source of reactive oxygen species (ROS). Water, another electronegative precursor, is also likely to be present in many biomedical applications because the devices are typically operated in open (humid) air and the plasma is in contact with moist biological targets.

In this letter, we report on the plasma dynamics observed in atmospheric-pressure rf microdischarges operated in electronegative gases and the fluxes of the chemically reactive species. Although all the figures shown correspond to $\mathrm{He}+\mathrm{H}_{2} \mathrm{O}$ plasmas, we have observed the same qualitatively dynamics in $\mathrm{He}+\mathrm{O}_{2}$, and similar behaviour is expected in other electronegative gases.

All the results presented here have been obtained using a conventional 1-dimensional fluid model that solves the continuity equation for each plasma species ( 31 species and 80 reactions $^{9}$ ), the electron energy equation and Poisson's equation. ${ }^{10}$ The chemistry model includes reactions of a pure helium discharge plus those listed in the simplified models S1 and S2 in ref. 9. Due to the large collisionality of the plasma $\left(v>>\omega_{\mathrm{rf}}\right.$ where $v$ is the electron-neutral collision frequency and $\omega_{\mathrm{rf}}$ the angular driving frequency), the charged particle inertia is neglected and the drift-diffusion approximation is used to determine their mean velocity. This model has been shown to be able to capture the main characteristics of atmospheric-pressure electropositive rf microdischarges sustained between two parallel plate electrodes ${ }^{11}$ and is now used here to study electronegative discharges. For comparison purposes, the $\mathrm{rf}(13.56 \mathrm{MHz})$ input power is kept constant at $1 \mathrm{~W} / \mathrm{cm}^{2}$ for all the discharges.

Fig. 1 shows the spatio-temporal evolution of the net space charge in microdischarges of varying gap size with different gas chemistry. The first row [Fig. 1(a)-1(c)] shows the case of a pure helium (electropositive) discharge. The oscillating motion of the electron ensemble during an rf cycle can be 
inferred by the location of the quasineutral region. As the gap size is reduced, the size of the quasineutral plasma decreases and the sheath width becomes comparable to the discharge gap. As a result, the quasineutral region (bulk plasma) starts to oscillate between the two electrodes, similarly to the observations reported elsewhere. ${ }^{5,6}$

The introduction of $\mathrm{H}_{2} \mathrm{O}$ into the feed gas (rows 2 to 4 in Fig. 1) results in the formation of negative ions, primarily $\mathrm{OH}^{-}$and its hydrated clusters $\mathrm{OH}^{-}\left(\mathrm{H}_{2} \mathrm{O}\right)_{\mathrm{n}}$, leading to an increasing electronegativity of the discharge. ${ }^{12,13}$ In conventional large-scale plasmas, this results in the stratification of electrons and anions due to their different mass and temperature, appearance of double layers (not shown explicitly here) and shrinkage of the sheaths [compare Fig. 1(c) and Fig. 1(1)]. ${ }^{14,15,16,17}$

While in large $(>1 \mathrm{~mm})$ discharges the stratification of electrons and anions does not result in a complete separation of the two species, in microplasmas where the sheath width becomes comparable to the gap size, electrons and anions are separated [Fig. 1(d), 1(g) and 1(j)]. Anions remain confined to the center of the discharge as their large inertia prevents them from responding significantly to the applied rf electric field. Their small oscillation can be observed in Fig. 1(d), 1(g) and 1(j) by following the central line of low charge density. This electronegative core becomes wider and stronger as the anion density increases with increasing water content. On the other hand, the more mobile electrons sweep the gap from electrode to electrode, moving across and beyond the central electronegative core and creating island of positive space charge between the electron ensemble and the central anions. This separation of electrons and anions is only observed in electronegative microplasmas (gap size $<1 \mathrm{~mm}$ for the conditions considered here).

The main ionization pathway to sustain the discharge changes with gap size and water concentration. For large gaps $(\geq 1 \mathrm{~mm})$, the main ionization mechanism shifts from helium and helium dimer metastable pooling reactions in a pure He discharge, to Penning ionization of water molecules at water concentrations of 100-1000ppm, and to detachment and direct ionization of water molecules at even higher water content. This shift results in the different electron generation spatio-temporal profiles shown in columns 2 and 3 of Fig. 2. As the gap size reduces, however, microplasmas shift to operate in a diffuse $\gamma$-mode where electron avalanches in the sheath become the main electron generation mechanism that sustain the discharge. ${ }^{6,11}$ This can be observed in Fig. 2, where for the $500 \mu \mathrm{m}$ discharge electron generation is mostly confined inside the sheaths as a result of direct electron impact ionization of helium and water (if present). These avalanches are initiated by electron emission from the electrodes, Penning processes in the sheaths, ${ }^{11,18}$ and, at high water content, also as a result of electron detachment from anions in the sheaths. 
While plasma dynamics are interesting from a scientific point of view, particle fluxes drive the interest of microplasmas for most applications. Here we show that microdischarges offer not only interesting dynamics but also a route to efficient delivery of both neutral and charged species. $\mathrm{He}+\mathrm{H}_{2} \mathrm{O}$ plasmas are known to produce valuable $\mathrm{ROS}^{9,19}$ such as $\mathrm{OH}$ and $\mathrm{H}_{2} \mathrm{O}_{2}$ that are of interest for biomedical and remediation applications. Typically, the flux of these species to the electrodes increase as the gap is reduced [Fig. 3(a) and 3(b)], a tendency that is attributed to the higher concentration generated in the discharge as a result of the increased power density and higher mean electron energy.

The increased drift of electrons against the electrodes as the gap decreases (see fig. 1) results in larger (and more energetic ${ }^{6}$ ) electron fluxes. Since no dc current flows through the system, a commensurable increase in the positive ion flux as the gap decreases is expected. This is explicitly shown in Fig. 3(c).

Beside neutral species and positively charged ions, anions can also be of interest for applications. For example, $\mathrm{O}_{2}^{-}$is an anion readily created in $\mathrm{He}+\mathrm{O}_{2}$ plasmas that plays an important role in oxidative stress responses in biology, ${ }^{20}$ and therefore of interest in plasma medicine. Anions are primarily confined in the central electronegative core by the ambipolar field created in the plasma (see Fig. 1). Nevertheless, some anions can manage to escape the discharge and indeed fluxes of negative ions have been detected in $\mathrm{He}+\mathrm{H}_{2} \mathrm{O}$ atmospheric-pressure plasmas by means of mass spectrometry. ${ }^{12}$ Interestingly, despite the decreasing electronegativity of the discharge as the gap is reduced (not shown explicitly), the anion flux to the electrodes increases (see Fig. 3(d)). Due to the large collisionality of atmosphericpressure discharges and the confining ambipolar field only anions that have been created in the electrode vicinity during the sheath collapses may manage to escape. Therefore, in atmosphericpressure plasmas, the anion flux and the bulk anion density are not necessarily proportional to each other. It turns out that the enhanced electron drift to the electrodes observed in microdischarges results in the presence of a larger number of electrons near the electrodes. This higher number of electrons leads to increased attachment, which in turns results in higher anion density near the electrodes and enhanced flux during the sheath collapse.

In conclusion, microplasmas offer an interesting approach for the efficient generation of neutral and charged species. The intricate dynamics of electronegative microplasmas result in the separation of electrons and anions and enhanced particle fluxes.

This work was supported by the Engineering Physical Science Research Council of UK, the National Natural Science Foundation of China, and the Fundamental Research Funds for the Central Universities of China. 


\section{FIGURE LIST}

Figure 1. Spatio-temporal evolution of the net space charge $\left(\times 10^{10} \mathrm{~cm}^{-3}\right)$. (a)-(c) Pure helium. (d)-(f) $\mathrm{He}+\mathrm{H}_{2} \mathrm{O} 300$ ppm. (g)-(i) $\mathrm{He}+\mathrm{H}_{2} \mathrm{O} 1000 \mathrm{ppm}$. (j)-(1) $\mathrm{He}+\mathrm{H}_{2} \mathrm{O} 3000 \mathrm{ppm}$. White lines delimitate the quasineutral regions. Images are not normalized to highlight their structure rather than their relative intensity.

Figure 2. Spatio-temporal evolution of the electron generation for the same conditions as in Fig. 1.

Figure 3. Fluxes of (a) $\mathrm{OH}$, (b) $\mathrm{H}_{2} \mathrm{O}_{2}$, (c) Positive Ions (predominately large water clusters $\left.\mathrm{H}^{+}\left(\mathrm{H}_{2} \mathrm{O}\right)_{n}\right)$, and (d) Negative Ions (predominately $\mathrm{H}^{-}$and large clusters $\mathrm{OH}^{-}\left(\mathrm{H}_{2} \mathrm{O}\right)_{\mathrm{n}}$ ) in a $\mathrm{He}+\mathrm{H}_{2} \mathrm{O} 3000$ ppm discharge. 

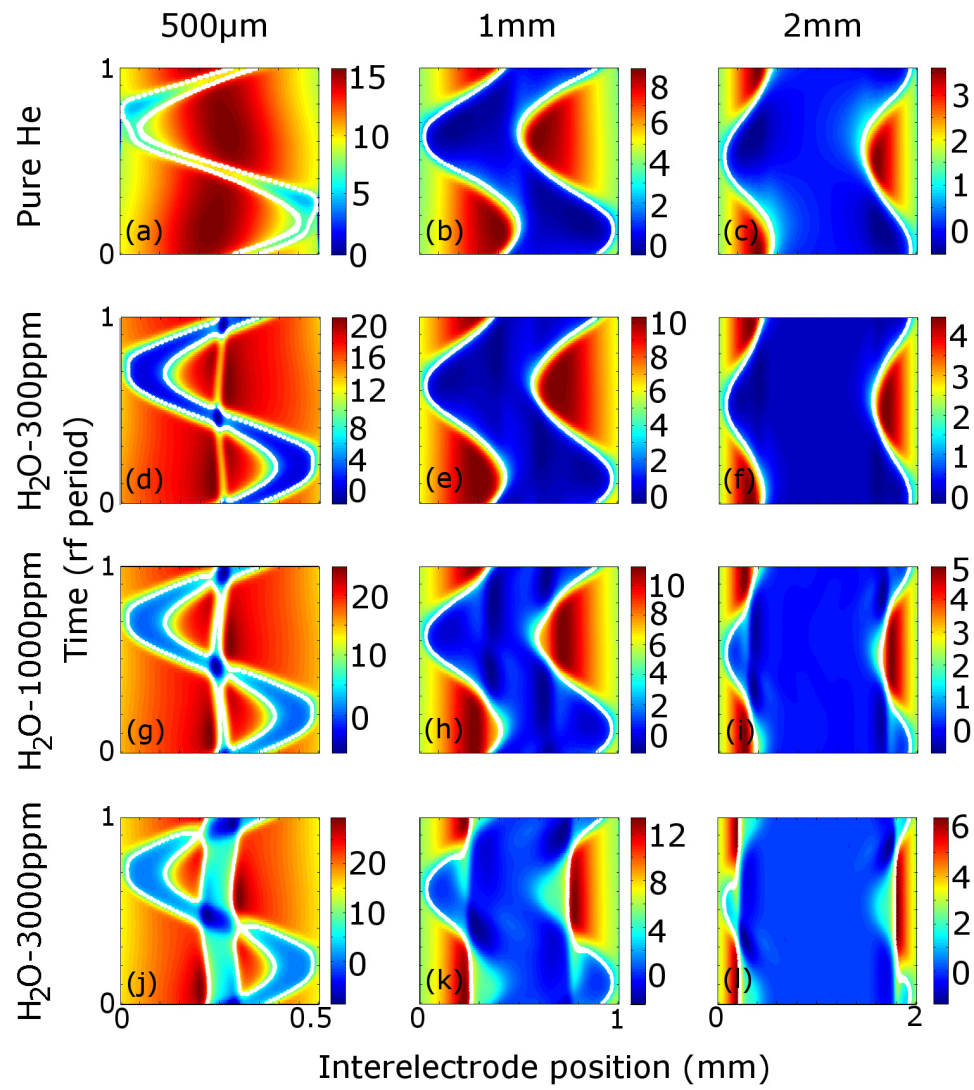

Figure 1. Spatio-temporal evolution of the net space charge $\left(\times 10^{10} \mathrm{~cm}^{-3}\right)$. (a)-(c) Pure helium. (d)-(f) $\mathrm{He}+\mathrm{H}_{2} \mathrm{O} 300 \mathrm{ppm}$. (g)-(i) $\mathrm{He}+\mathrm{H}_{2} \mathrm{O} 1000 \mathrm{ppm}$. (j)-(l) $\mathrm{He}+\mathrm{H}_{2} \mathrm{O} 3000 \mathrm{ppm}$. White lines delimitate the quasineutral regions. Images are not normalized to highlight their structure rather than their relative intensity. 


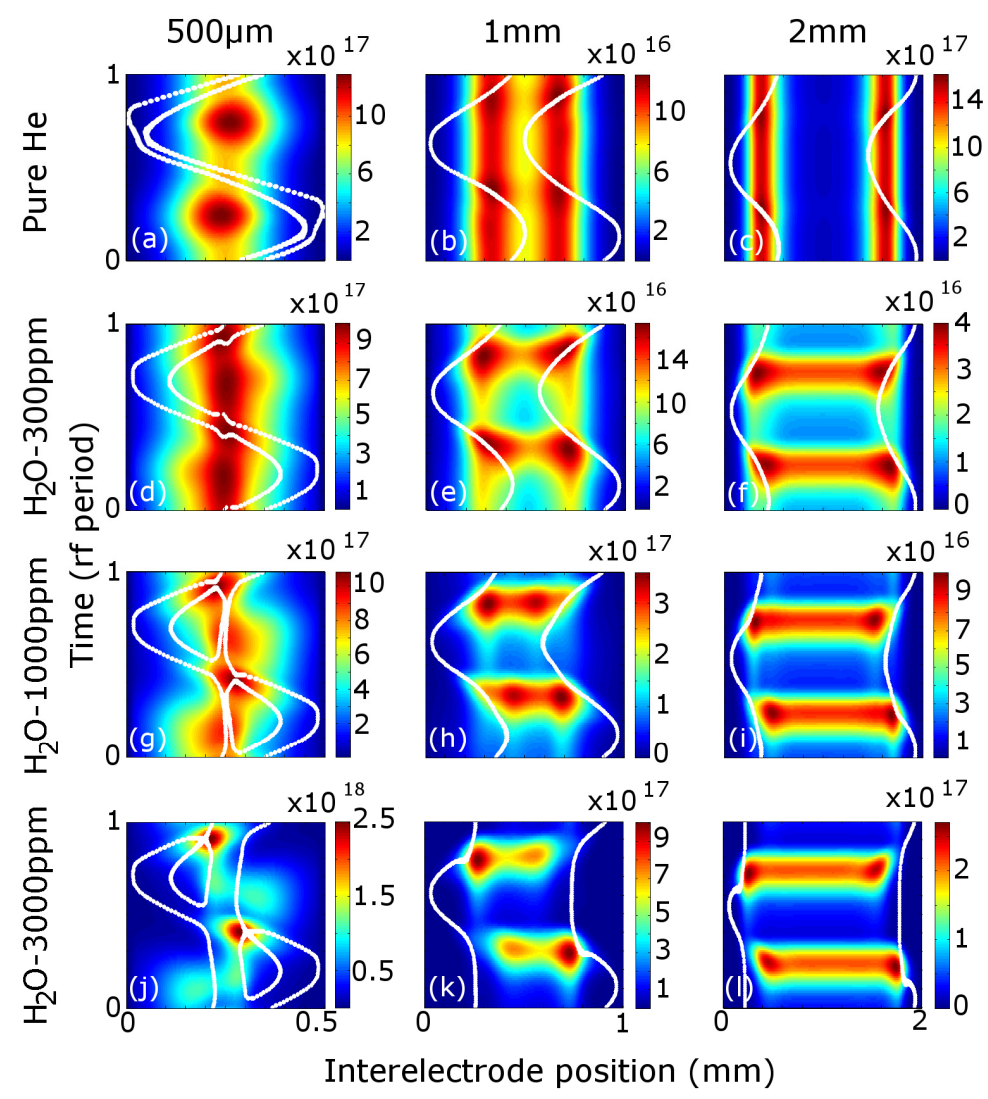

Figure 2. Spatio-temporal evolution of the electron generation for the same conditions as in Fig. 1. 
(a)

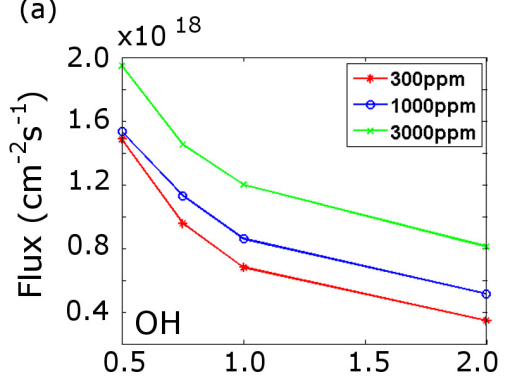

(c) Gap Spacing $(\mathrm{mm})$

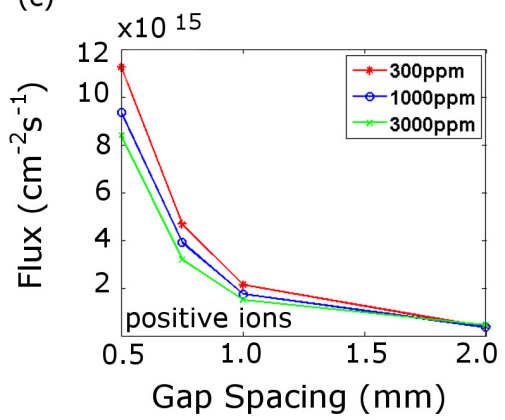

(b)

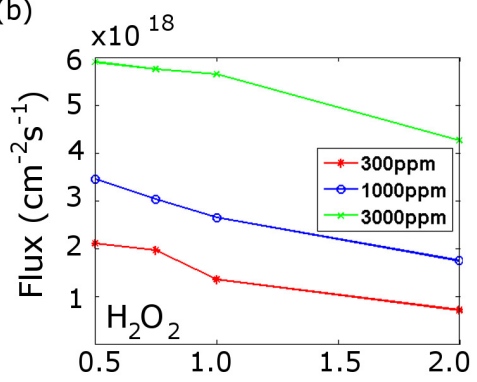

(d)

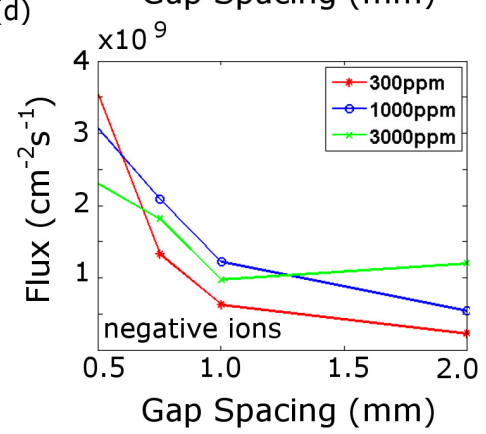

Figure 3. Fluxes of (a) $\mathrm{OH}$, (b) $\mathrm{H}_{2} \mathrm{O}_{2}$, (c) Positive Ions (predominately large water clusters $\mathrm{H}^{+}\left(\mathrm{H}_{2} \mathrm{O}\right)_{\mathrm{n}}$ ), and (d) Negative Ions (predominately $\mathrm{H}^{-}$and large clusters $\left.\mathrm{OH}^{-}\left(\mathrm{H}_{2} \mathrm{O}\right)_{\mathrm{n}}\right)$ in a $\mathrm{He}^{+}+\mathrm{H}_{2} \mathrm{O} 3000 \mathrm{ppm}$ discharge. 


\section{REFERENCES}

${ }^{1}$ K.H. Becker, K.H. Schoenbach, and J.G. Eden, Journal of Physics D: Applied Physics 39, R55 (2006).

${ }^{2}$ F. Iza, G.J. Kim, S.M. Lee, J.K. Lee, J.L. Walsh, Y.T. Zhang, and M.G. Kong, Plasma Process. Polym. 5, 322 (2008).

${ }^{3}$ N. Knake and V.S.-von der Gathen, The European Physical Journal D 60, 8 (2010).

${ }^{4}$ A.R. Hoskinson, J. Hopwood, N.W. Bostrom, J.A. Crank, and C. Harrison, J. Anal. At. Spectrom. 26, 1258 (2011).

${ }^{5}$ J.J. Shi and M.G. Kong, Phys. Rev. Lett. 96, 105009 (2006).

${ }^{6}$ F. Iza, J.K. Lee, and M.G. Kong, Phys. Rev. Lett. 99, 075004 (2007).

${ }^{7}$ G. Fridman, G. Friedman, A. Gutsol, A.B. Shekhter, V.N. Vasilets, and A. Fridman, Plasma Process. Polym. 5, 503-533 (2008).

${ }^{8}$ M.G. Kong, G. Kroesen, G. Morfill, T. Nosenko, T. Shimizu, J. van Dijk, and J.L. Zimmermann, New J. Phys. 11, 115012 (2009).

${ }^{9}$ D.X. Liu, P. Bruggeman, F. Iza, M.Z. Rong, and M.G. Kong, Plasma Sources Sci. Technol. 19, 025018 (2010).

${ }^{10}$ H.C. Kim, F. Iza, S.S. Yang, M. Radmilović-Radjenović, and J.K. Lee, J. Phys. D: Appl. Phys. 38, R283 (2005).

${ }^{11}$ D.W. Liu, F. Iza, and M.G. Kong, Appl. Phys. Lett. 95, 031501 (2009).

${ }^{12}$ P. Bruggeman, F. Iza, D. Lauwers, and Y.A. Gonzalvo, J. Phys. D 43, 012003 (2010).

${ }^{13}$ D.X. Liu, P. Bruggeman, F. Iza, M.Z. Rong, and M.G. Kong, Plasma Sources Sci. Technol. 19, 025018 (2010).

${ }^{14}$ J.-P. Boeuf, Phys. Rev. A 36, 2782(1987)

${ }^{15}$ T.E. Sheridan, Journal of Physics D: Applied Physics 32, 1761 (1999).

${ }^{16}$ S. Kim, M.A. Lieberman, A.J. Lichtenberg, and J.T. Gudmundsson, J. Vac. Sci. Technol. A 24, 2025-2040 (2006).

${ }^{17}$ D.D. Monahan and M.M. Turner, Plasma Sources Sci. Technol. 17, 045003 (2008).

${ }^{18}$ J. Waskoenig, K. Niemi, N. Knake, L.M. Graham, S. Reuter, V.S.D. Gathen, and T. Gans, Plasma Sources Sci. Technol. 19, 045018 (2010).

${ }^{19}$ D.X. Liu, F. Iza, X.H. Wang, M.G. Kong, and M.Z. Rong, Appl. Phys. Lett. 98, 221501 (2011).

${ }^{20}$ B. Halliwell and J.M.C. Gutteridge, Free Radicals in Biology and Medicine, 4th ed. (Clarendon Press, Oxford, 2007). 